\title{
Família i canvi social en una vila de la Catalunya vella ${ }^{1}$
}

\author{
Lluís Flaquer \\ Universitar Aurònoma de Barcelona. Departament de Soctologia \\ 08193 Bellaterta (Barcelona). Spain
}

\section{Resum}

Aquest article es refereix a la lenta erosió de les pràctiques jurfíques i socials tradicionals com a consequèencia de l'impacte de la industrialització i de la modernització de les explotacions agrícoles en una vila de la Catalunya vella en el període que segueix a la guerra civil. A principi dels anys quaranta l'economia de la zona era de caràcter agrari i la família troncal, Iligada a un sistema de successió indivisible, era la forma típica de convivencia. Quan, a principi dels anys seixanta, la industrialització forçà molts camperols a deixar les seves explotacions i emigrar cap a la zona urbana a la recerca de noves oportunitats econòmiques, el sistema familiar va començar a canviar. Mitjançant l'anàlisì d'una mostra de més de 500 matrimonis, aquest article examina el procés de transformació familiar i descobreix especialment la capacitat de tesistència al canvi de la familia troncal, la qual, malgrat ser una institució en davallada en les condicions modernes, s'ha adaptat prou bé a la nova situacio, tant en les explotacions agricoles com en la zona urbana.

Paraules clau: família, canvi social, tipus de família, matrimoni.

\section{Abstract. Family and social change in a Catalan village}

This article is concerned with the slow erosion of traditional legal and social practices under the impact of industrialisation and of modernisation of farming in a rural district of Northern Catalonia (Spain) in the period following the Spanish Civil War (1936-1939). In the early 1940's the economy of the area was agrarian in character and the stem family, tied to a system of impartible inheritance, was the typical domestic and residential arrangement. When in the early 1960's industrialisation set in and many peasants left their farmsteads to migrate to town in search of new economic opportunicies, family form was bound to change. Through a survey of over 500 cases of marriage, the paper examines the

1. I a recollida de les dades d'aquesta recerca fou realitzada entre 1977 i 1982. Voldria agrair la gentilesa de l'Ajuntament de Besalú pel seu ajut desinteressat, així com la col.laboració de centenars d'informants del poble sense els quals aquesta investigació no s'hagués pogut portar a terme. Per últim, haig de manifestar la meva graticud a Jordi Vinyeta, que ha participat efiçaçment en l'actualització de les dades. 
process of family transformation stressing the resilience of the stem family which, although a decaying institution in the modern conditions, has adapted well to the new situation boch in the farming and the urban area of the rural district.

Key words: family, social change, family types, marriage.

\section{Sumari}

$\begin{aligned} \text { Introducció } & \text { Resultats de la recerca } \\ \text { Característiques i evolució recent } & \text { Reforma legislativa i canvi familiar } \\ \text { de la comunitat objecre d'estudi } & \text { Conclusió } \\ \text { Plantejament de la recerca } & \text { Bibliografia }\end{aligned}$

\section{Introducció}

Un deis problemes més fascinants de la sociologia del dret és la relació entre les institucions jurídiques i la realitat social i econòmica. En aquest sentit, l'estudi dels processos pels quals una institució jurídica predominant perd la seva força i s'adapta a les noves condicions o és reemplaçada per altres pràctiques que esdevenen insritucionalizzades en el decurs del temps sota l'impacte de les canviants condicions econòmiques, constitueix un camp d'invesrigació molt prometedor. En aquest article intento il-lustrar la complexitat d'aquests processos de canvi a través d'un cas concret, la transició d'una forma familiar a una alrra en una petita vila de la Catalunya vella durant el període que comprèn des del final de la Guerra Civil fins al present.

Per transició familiar entenc el procés mitjançant el qual una forma familiar predominant és reemplaçada per una altra en una societat donada. Com es desprendrà del meu treball, no necessita correspondre's exactament amb altres classes de transició social, tals com el procés d'industrialització, el canvi d'un mode de producció a un altre o la transició demogràfica, malgrat que indubtablement hi està associada.

Prenc forma familiar en el sentit donat a aquesta expressió per Harris (1986), qui fa la distinció entre forma i caràcter familiars. $\mathrm{La}$ forma familiar es refereix a un conjunt de regles relatives a la formació d'un grup mitjançant les quals una estructura familiar particular és reprodurida en el temps a través de les generacions. El caràcter de la família es refereix al contingut d'aquestes formes, és a dir, a la natura de les relacions humanes en el grup familiar, l'estructura emocional que produeix i l'interior psicològic de la família. Forma i caràcrer familiars no necessiten correspondre's l'una amb l'altra. Tot i que la relació entre forma i caràcrer és un camp d'estudi molt interessant (Harris, 1983; Kellerhals i altres, 1984), aquest article no el tractarà.

La forma familiar va normalment lligada a les institucions jurídiques socials, però especialment en períodes de transició és el resultat de pràcriques 
socials que poden o no esdevenir institucionalizzades en el decurs del temps. Això planteja el problema de com cal valorar el predomini d'una institució en una societat donada. Per descomptat, l'única forma de confirmar la força d'una institució és veure fins a quin punt la gent encara acata les seves normes, però el predomini d'un nombre de pràctiques no significa necessàriament que una institució vella encara tingui força o que n'estigui emergint una de nova.

Totes aquestes qüestions en disputa vénen a tomb quan ens apropem al tema de la transició de la forma de família troncal a la nuclear. En aquest article il.lustraré la complexitat d'aquesta transició fent servir un cas, i suggeriré una aproximació per mesurar el predomini de la família troncal en una comunitat donada, una aproximació que està basada en la consideració del procés familiar més que no pas en la composició de la llar. En la primera part de l'article descriuré les característiques principals de la comunitat estudiada i la seva evolució recent. La segona i la tercera part de l'article estaran dedicades respectivament a la discussió dels problemes que presenta l'esrudi de la família troncal $\mathrm{i}$ als resultats a què va arribar la meva investigació.

\section{Característiques i evolució recent de la comunitat objecte d'estudi}

L’àrea estudiada en aquest article comprèn els municipis de Besalú, Sant Ferriol, Beuda, Maià de Montcal i Dosquers que, dins la comarca de la Garrotxa, formen plegats una certa unitat comercial amb Besalú al seu centre com a vila de serveis. Em referiré a aquest conjunt de municipis com l'àrea de Besalú. És una àrea muntanyosa dividida en dues meitats pel riu Fluvià, que flueix cap a l'est. La vila de Besalú és a la vall d'aquest riu, prop d'on estan situades la majotia de les terres de conreu. La resca de l'àrea és bosc, majoritàriament alzines, pins i sotabosc.

El $70 \%$ de la població de l'àrea està concentrada en el nucli de Besalú, que cobreix només el $5 \%$ de la superfície total. L'alta densitat de població de Besalú contrasta amb la de Beuda i Sant Ferriol, que són en major part àrees muntanyoses, i en menor grau amb la de Maià, que és majoritàriament una àrea plana de conreu amb poblament dispers. La marcada oposició entre la vila de serveis $i$ la resta no sempre ha existit. El 1857, quan es va fer el primer cens modern, la població del nucli representava, aproximadament, un terç de la gent que vivia en tota l'àrea, $i$ la rodalia rural estava reblerta amb centenars de masos on els pagesos amb prou feines es guanyaven la vida. Les proporcions pràcticament s'han invertit el 1975. La població de la rodalia de Besalú ha anat declinant continuadament des de l'any 1857 , no només en termes absoluts, sinó també en termes de la seva proporció respecte al total de la població de l'àrea. La població del nucli urbà va romandre quasi estancada en termes absoluts amb una petita tendència al decreixement fins al 1960, tot i que guanyava terreny en termes de la proporció de la totalitat de la comunitat que representava. Entre 1960 i 1975 el creixement del nucli de Besalú fou realment espectacular, i en 15 anys es va incrementar en un $60 \%$. El cens de 1981 mostra la contínua caiguda de població de la rodalia de Besalú (vila de Besalú, 
2091 persones; rodalia de Besalú, 713 persones). En el darrer decenni la població del nucli urbà mostra una tendència a l'estancament, mentre que la de la resta de l'àrea ha continuat disminuint. Així, segons el cens de 1991, a Besalú viuen 2098 persones i a la rodalia 656.

Aquestes dades semblen suggerir que abans de 1960 les migracions de la rodalia de Besalú no eren cap al nucli, sinó arreu, mentre que a partir de 1960 el creixement del nucli urbà va ser, fins a un cert punt, el resultat de la immigració dels camperols de la rodalia.

La societat tradicional de Besalú, com bona part de la Catalunya vella, tenia una mena de pauta de poblament diferenciada que inflüa en molts aspectes de la vida social, com ara la familia i la residència. Aquesta forma d'assentament dispers estava associada a un mode particular d'explotació de la terra que anomenaré el sistema de masos. La paraula mas descriu sobretot una casa de pagès i les seves dependències, però també denota una forma d'explotació de la terra i un model de residencia i poblament.

Cada mas tenia un nom mitjançant el qual no només eren coneguts la casa de pagès i els camps adjacents, sinó també els seus residents. Un mas era també, com un sistema, un conjunt integrat de terres i camps disposats d'una manera determinada al voltant de la casa de pagès i una mena d'explotació de la terra. El sistema de masos estava basat, tradicionalment, en una explotació de conreu múltiple altament diversificat que idealment apuntava cap a l'autosuficiència. En una economia caracteritzada per una circulació limitada de diner i una escassa relació amb el mercat nacional i internacional, el mas proporcionava als seus habitants la majoria dels productes que necessitaven.

La noció de mas com a unitat autosuficient implicava la conveniència de la seva permanència en el temps com un tor integrat. L'amputació d'una part del mas, una unitat econòmica viable en el context d'un model tradicional de subsistència, podia donar lloc a un ràpid procés de desintegració i extinció. D'aquí la necessitat de transmissió de la totalitat de la finca d'una generació a una altra. L'herència indivisible pot ser vista com una solució adaptativa per a la continuïtat i operativitat del sistema de masos, i aquest mode d'herència ha estat associat sovint amb la família troncal.

El dret successori català estableix la regla de primogenitura masculina (Brocà y Amell, 1880; Maspons, 1935 i 1938; Sardà, 1962). Això significa que el primer fill, immediatamenr després del seu naixement, ocupava la posició de futur hereu, no només als ulls dels membres del grup domèstic, sinó als de la totalitat de la comunitat. Nogensmenys, si ell no satisfeia les expectatives del seu pare o si no era apte per al bon govern del mas, el cap de família podia designar un altre dels seus fills o filles. D'acord amb el dret successori català, una filla només podia ser hereva (pubilla) en absència de descendència masculina. L'hereva designada era la filla més gran. Els fills més joves exclosos de l'herència eren anomenats fadristerns.

Una de les raons per a la incapacitació d'un presumpte hereu era, a més de la mala salut i del retardament mental, la seva tardança a trobar una esposa adient passat un període de temps raonable. Si romania solter, això no només 
podia posar en perill la continü̈tat del llinatge i del mas, sinó que també podia possiblement suposar una pèrdua de seguretat per l'ancianitat dels seus pares. Les dues parts de l'associació, presumpte hereu i cap de família, estaven interessats a assegurar l'estabilitat per a les seves vides futures. Per aquesta raó primordial els pares sovint eren reticents a renunciar al control de la finca, tement que el futur hereu no portés la seva muller a viure al mas i no tingués cura de la parella vella quan s'apropés el moment de la seva jubilació. D'altra banda, el futur hereu tractava de garantir la seva posició, ja que es donaven casos de pares que, en la seva vellesa, com a resultat d'un caprici passatger, havien canviat d'opinió en l'últim moment i havien designat un altre fill com a hereu.

La solució tradicionalment adoptada per evitar aquest conflicte d'interessos era la pràctica d'una forma contractual d'herència, una institució típica del dret successori català. Aquesta classe de transmissió de propietat (heretament) era acordada com a una de les clàusules del contracte de matrimoni. Els capítols matrimonials eren acords entre totes les parts involucrades en un matrimoni (normalment el nuvi, la núvia i llurs pares) interessats a determinar les relacions econòmiques entre els esposos. Ets capítols matrimonials catalans podien ser acordats abans o després del matrimoni, però un cop acordats eren irrevocables. La seva validesa era, en qualsevol cas, condicionada a la celebració del matrimoni, car no tenien efecte per la mera signatura del contracte, sinó per l'acte del matrimoni.

Quan el nuvi era un hereu, un dels pactes més freqüents dels capítols era l'heretament. Mitjançant aital clàusula, el cap de família donava al seu fill successor tota o la majoria de la seva propietat després de la celebració del matrimoni. Els heretaments eren de dues classes (Maspons, 1935, p. 29-31). Els heretaments basats en donacions presents eren simplement un acte jurídic mitjançant el qual el pare transferia totes les seves propietats presents al seu hereu, mentre que es reservava per a si mateix i la seva esposa el dret d'usdefruit vitalici. No vaig trobar a l'àrea de Besalú contractes que continguessin heretaments d'aquesta classe. D'altra banda, les donacions futures eren molt comunes. Mitjançant aquesta classe de clàusula contractual el donant designava el seu fill com a hereu universal de la propietat posseïda a la seva mort. D'acord amb aquesta estipulació contractual el pare retenia la totalitat del control de la propietat fins a la seva mort, però les expectatives del seu fill pel que feia a l'herència estaven garantides. A l'inrevés que en el cas del testament, els termes del qual podien ser canviats pel desig del testador, un heretament mai no podia ser revocat, $i$ això conferia una gran seguretat al seu beneficiari.

Un heretament era, en qualsevol cas, una donació condicionada o una promesa d'herència. En els capítols examinats com a part d'aquesta investigació es mencionaven dues condicions: Primera, l'hereu designat i la seva dona eren obligats a residir amb el donart i la seva esposa, això és, l'herència a la mort del pare estava condicionada a la residència comuna. Segona, el pare del nuvi estava obligat a mantenir el seu hereu i l'esposa d'aquest amb la condició que "ells el respectessin com a pare i treballessin per al seu benefici i utilitat", d'acord amb la fórmula sovint utilitzada. 
Si el donant moria abans que la seva esposa, l'hereu estava obligat a mantenir la seva mare, una clàusula que intentava impedir que l'hereu la deixés desemparada, ja que ell obtenia la totalitat del títol de propietat a la mort del seu pare. Hi havia uns altres capítols que tractaven d'assegurar els drets de la mare establint l'usdefruit de la propietat a nom seu mentre la designava com a "senyora i majoran, una expressió que volia dir cap de família.

Els contractes de matrimoni també regulaven el resultat d'una possible dissolució de l'associació residencial econdmica. El pacte més corrent era que en cas d'un desacord (desavinença) que comportés la marxa de la parella jove del mas, el pare es comprometia a donar al seu fill una quarta part de la seva propietat en el moment de la separació. La quota era fixada per dos parents escoliits per les dues parts. La separació del grup residencial comportava en ella mateixa la revocació del contracte i de la designació del fill que marxava com a hereu, $i$ així el pare era lliure de fer nous acords amb un altre dels sets fills.

Les regles d'herència catalanes poden ser descrites com una varietat de la pràctica successòria basada en el dret de beneficiar un fill en detriment dels altres. Aquest sistema d'herència està sovint relacionat amb el terme francès de préciput (Yver, 1966; Le Roy Ladurie, 1976; Sabean, 1976; Lamaison, 1979). Les lleis d'herència catalanes segueixen, de manera molt estricta, la llei romana. D'acord amb les normes romanes, el testador no podia ometre cap dels seus fills en el seu testament sense desheretar-lo expressament. La preterició, és a dir, l'omissió d'un, implicava la nul.litat del testament. Seguint les regulacions romanes el testador no podia disposar lifurement d'una quarta part de la seva propietat i aquesta part, anomenada "ilegítima", havia de ser deixada als familiars més propers (Iglesias, 1958, p. 628-633). De manera semblant, el dret successori català estableix una petita llegítima de només un quart. Aquesta quota ha de ser dividida equitativament entre tots els fills del testador i normalment pagada en efectiu (Brocà y Amell, 1880, p. 422-442; Maspons, 1938, p. 78-82; Compilación, 1960, p. 91-93).

Tret que les quotes de llegitima ja haguessin estat pagades pel pare o per la mare durant la seva vida en forma de dot, educació, regals, etc., la responsabilitat de la seva liquidació requeia sobre l'hereu. Els contractes de matrimoni sempre tenien una clàusula on s'especificava l'obligació dels hereus de dotar els seus germans petits (fadristerns) amb la seva part de llegítima i les seves germanes amb un dot. Com que no hi havia terme per pagar la llegítima, la incapacitat de l'hereu per liquidar-la en un període raonable de temps, per manca real o suposada de liquidesa, era una constant font de conflicte entre germans i duia a litigis sense fi.

Si el pare no tenia nois però tenia filles per casar, en podia designar una com a hereva, normalment la més gran (pubilla). Lhereva tenia els mateixos drets que si fos l'hereu i les regulacions dels contractes de matrimoni referents a la pubilia eren si fa o no fa el mateix que els de l'heret. L'home que es casava amb una pubilla era anomenat pubill i havia de pagar una contribució en efectiu, funcionalment equivalent al dot, anomenada "aixovar".

Amb aquest sistema de normes de successió basades en la indivisibilitat de 
I'herència, que intentava preservar la integritat de la finca, només l'hereu (o eventualment la pubiila) podia casar-se i portar el/la seu/va espòs/a al mas. La resta de fills eren forçats a establir-se en un altre lloc. En qualsevol cas, els fills no hereus podien restar al mas amb la condició de romandre solters. El grup domèstic podia incloure mossos i les llars més riques a vegades minyones, els quals estaven obligats a romandre solters com els fadristerns o les filles no hereves si volien mantenir el seu lloc de treball.

No tots els membres de la comunitat de Besalú acostumaven a determinar les condicions economiques dels matrimonis per contracte. Els contractes de matrimoni només tenien sentit quan les parts involucrades tenien propietats, especialment terres. Ara bé, la majoria dels pagesos de la comunitat rural eren masovers $i$, per tant, no podien transmetre als seus fills cap dret sobre la rerra. De fet, els matrimonis que implicaven la unió d'hereus propietaris de terres representaren una cinquena part del total de matrimonis de l'àrea de poblament dispers en el període de 1941-1975, malgrat que aquesta proporció tendia a disminuir en les àrees de muntanya. Tanmateix, la majoria dels masovers, tot i no tenir cap mena de contracte escrit o formal, tendien a formar families troncais amb llinatges molt similars als dels propietaris. En aquest cas, el fill més gran era l'únic a qui hom permeria dur la seva muller al mas i accedir a la terra a la mort del seu pare. Sembla que els propietaris toleraven aquesta pràctica successòria donat el gran nombre de famílies troncals formades amb aquesta classe d'acords.

A la dècada dels anys quaranta i cinquanta els pagesos no propietaris eren majoritàriament masovers. El contracte de masoveria que definia els drets i les obligacions del propietari i del masover tenia moltes semblances amb el sistema de mezzadria típic del centre d'Iràlia descrit per Silverman (1968), Kertzer (1977) i Byres (1983). Mitjançant aquest contracte, el propietari es comprometia a arrendar el mas al masover per un període de temps donat amb l'obligació d'aquest de viure-hi amb la seva família, cultivar-ne la terra i pagar-li com a preu d'arrendament una quota que podia variar des d'un terç fins a la meitat de la collita (Vilà, 1973, p. 175). Cal tenir en compte que, tot i que el contracte era entre el propietari i el masover, aquest darrer no era considerat en l'esperit de l'acord com a individu, sinó com a cap d'un grup domèstic, els membres del qual eren requerits a viure en el mas i explotar-lo.

Malgrat que la Llei d'Árrendaments Rústics de 1935 donà el dret d'estada permanent als masovers mentre paguessin la seva renda, després de la guerra els propietaris podien, de fet, reemplaçar els seus parcers sense gaire interferència jurídica. Els contractes eren verbals i es renovaven anualment al final de cada anyada agrícola, que finalitzava per Nadal.

D'acord amb els termes del contracte de masoveria, l'aparcer havia de pagar al propietari d'un terç a la meitat de la collita, encara que aquesta proporció podia variar d'acord amb la qualitat de la terra i la mena de productes. D'aquest pagament en espècie estaven exempts els productes de l'hort que el masover cultivava per a consum propi i aquella quantitat de terra fixa assignada pel conreu d'userda i altres farratges per a animals de càrrega $i$ altres animals des- 
tinats al consum propi. Els animals de càrrega pertanyien al masover, que era responsable de la seva aportació i alimentació, i depenia d'ell pagar els impostos derivats de la seva propietat.

Sota les disposicions del significat original del contracte, propietari i masover havien de fer diferents contribucions a la producció agrícola. El propietarì havia de proporcionar al masover no només la terra, sinó també eis adobs i les eines agricoles $i$ havia de donar-li indicacions sobre el conreu de la terra (Vilà, 1973, p. 175). En qualsevol cas, a final dels anys cinquanta i a principi dels anys seixanta, si no abans, la participació activa del propietari en la marxa del conreu va tendir a disminuir.

Aquesta menor participació del propietari en el conreu segurament va ser deguda a l'estesa pràctica de l'absentisme. Als anys quaranta vivien en l'àrea de la rodalia de Besalú tan sols aquells propietaris que conreaven directament liurs explotacions d'extensió mitjana i només uns pocs propietaris rendistes que vivien en les seves masies prop de la vila. La resta de grans propietaris vivien a la vila de Besalú o àdhuc en viles i ciutats distants.

Abans de continuar, hem de dir unes poques paraules sobre aquests propietaris rendistes. En primer lloc, els membres de la classe dels grans terratinents formaven una petita aristocràcia endogàmica amb xarxes esteses per tot Catalunya que afavorien les relacions de patronatge amb els setus masovers. Aquells que vivien en les seves terres rebien l'apel-latiu d'amos, un terme que deixava ben clara la seva superioritat econòmica i la seva inflùencia social. En segon lloc, els rendistes possë̈dors de grans propietats, a més de rebre la renda de la terra dels seus masovers, tenien altres fonts d'ingressos, com ara els procedents de la venda d'alzines per a llenya i carbó. Els boscos no eren mai arrendats, car el propietari explotava tots els seus productes directament (fusta, caça, pastures, etc.). En tercer lloc, quan hi havia eleccions abans de la guerra, un terratinent solia demanar als seus masovers que votessin per un candidat concret seguint el sistema del caciquisme.

Pel que fa als treballadors sense terra, la quarta classe agrària important, vivien com els terratinents rendistes en el nucli de Besalú. El 1940 representaven una cinquena part de la població treballadora de la vila i formaven en gran part famílies nuclears. Treballaven majoritàriament per als grans terratinents a I'hivern (com a llenyataires, carboners, etc.) i eren contractats pels pagesos que correaven terres d'extensió mitjana a la temporada d'estiu.

La marcada delineació d'aquestes categories agràries no ens ha de fer creure que els seus membres fossin radicalment diferents. Deixant de banda els terratinents rendistes que exercien una gran influència política i econòmica, tots havien de treballar molt dur per poder guanyar-se la vida. Els petits propietaris que explotaven directament les seves terres tendien a confondre's amb els masovers acomodats. D'altra banda, els petits masovers havien de treballar com a jornalers per als grans propietaris durant el llarg període d'inactivitat de l'hivern, i la majoria dels treballadors sense terra tenien axrendat un petit hortet prop del riu Fluvià, a una distància de cinc minuts a peu des de la vila, i d'altres fins i tot una petita patcel-la fora de Besalú. 
Aquesta economia agrària tradicional integrada va començar a canviar a final dels anys cinquanta. A. l'hivern de 1956 la majoria de les oliveres es varen gelar i moriren poc després. Això va trencar l'autosuficiència de la majoria dels masos, però també va afectar fortament l'economia dels grans terratinents que conreaven oliveres i posaven a la venda oli d'oliva. D'altra banda, l'expansió industrial com a resultat de les reformes econòmiques de 1958 afavorí un conreu amb més inversió de capital, més especialitzat i més orientat al mercat. En el decurs dels anys seixanta molts dels petits masovers, particularment aquells que vivien a les àrees de muntanya, trobant-se mancats de capital per modernitzar les seves explotacions, les petites parcel-les disperses de les quals feien inviable la seva mecanització, van haver de deixar els seus masos i emigrar a la vila a la recerca de noves oportunitats econòmiques.

Cap al principi dels anys seixanta van començar a aflorar noves indústries a Besalú. En la majoria dels casos això no fou producte de la introducció de capital foraster dins la comunitat, sinó més aviat el resultat de la modernització d'indústries tradicionals, de caracter artesanal. Aquest va ser el cas de les abriques de nova planta de guix, calç, sabates, tèxtil i paper, totes les quals eren activitats econòmiques dutes a terme des de principi de segle utilitzant tecnologia tradicional i que ocupaven un reduitt nombre de persones.

Aquest rapidissim creixement de les fâbriques comportà l'augment de dues classes socials noves: els industrials i els treballadors industrials. Com he dit, els industrials eren generalment persones nascudes a la comunitat, que abans de l'onada de la industrializzació dels anys seixanta eren homes de negocis a petita escala. El seu poder $\mathrm{i}$ influència van anar creixent els anys seguients fins que varen desplaçar l'ascendent dels grans trerratinents, els quals, en la seva major part, s'havien absentat permanentment de Besalú en no poder viure només de les rendes de la terra com a resultat de les noves condicions.

D'altra banda, els treballadors industrials eren en la seva majoria antics pagesos, sobretot petits parcers i masovers que no van poder sortir-se'n amb les noves condicions de conreu. La proporció de treballadors industrials en la població treballadora de Besalú es va incrementar del $14.5 \%$ l'any 1940 fins al $60.1 \%$ el 1975 . El fet que la majoria fossin immigrants dels poblets veïns, i especialment de la rodalia de Besalú, proporciona una bona oportunitat per tal d'estudiar la transició de la família troncal pagesa a la nuclear.

\section{Plantejament de la recerca}

La investigació del canvi de les formes familiars com a resultat de la industrialització requereix l'elaboració d'un nombre de tècniques de recerca que convindria comentar. Quan la comunitat objecte d'estudís és d'una dimensió considerable (al voltant de 3.000 persones), geogràficament diferenciada en un nucli urbà i una zona rural de poblament dispers, socialment heterogènia, amb una diferenciació social creixent al llarg dels anys $i$, en general, amb una estructura social que experimentà una transformació radical entre els anys 1940 i 1975 , aquesta mena d'investigació presenta una colla de dificultats. 
En primer lloc, cal examinar quina és la situació "inicial» en termes del predomini de les diferents formes familiars per tal de poder-ne investigar els canvis. Idealment convé disposar d'un indicador de la importància de cada forma, segons les diferents categories socials i geogràfiques. Quan dos tipus de formes familiars coexisteixen, com en el cas que ens ocupa, sorgeixen unes altres dificultats. A més, l'estudi de la família troncal ha donat lloc a un nombre de problemes de conceptualització i mesurament del seu predomini (Parish i Schwartz, 1972; Berkner, 1972a; Wachter i altres, 1978; Laslett, 1972; Wheaton, 1975; Verdon, 1979, 1980; Fine-Souriac, 1977; Augustins, 1977; Flaquer, 1984).

Bàsicament, quan s'utilitzen dades censals allò que podem estudiar en una poblacío donada és la distribució dels diferents tipus de liars, classificades segons la seva composició. Els grups residencials que apareixen en les dades d'un cens són el resultat d'un cerr nombre de processos, associats amb les instirucions jurídiques i socials, que expressen, al setu torn, el funcionament d'un mode de producció i que constitueixen el que anomenem una forma familiar. Aquests processos són mediatitzats per un nombre de factors demogràfics i econòmics els efectes dels quals no poden ser destriats tan facilment. Per exemple, la proporció de llars amb tres generacions només ens dóna una idea molt imperfecta del funcionament de les normes de la família troncal. Com ha mostrat Berkner (1972a), quan l'esperança de vida és baixa, la proporció d'aquestes llars serà també baixa en una població que tingui com a forma familiar tipica la família troncal. Si estem investigant un perfode en què la població experimenta canvis demogràfics dràstics tals com l'augment de l'esperança de vida i la disminució de l'edat de matrimoni, i no tenim en compte aquests factors, l'augment de la proporció de llars amb tres generacions podria ser considerat erròniament com a indicador del creixement de la incidència de la família troncal.

Els censos són com una instantània d'una població donada $i$ el que ens cal són pel-lícules. Hi ha sempre un punt crític en el cicle de la vida dels grups domèstics en el qual es transformen mitjançant la incorporació de membres nous i la separació dels vells. Per anàlisi generativa em refereixo a la investigació del procés que condueix a la formació i dispersió de grups domèstics, centrant especialment l'atenció en aquests punts crítics. En aquesta mena d'anàlisi diacronica l'investigador intenta identificar els processos que determinen certes configuracions residencials més que no pas limitar-se a examinar llur composicib. El matrimoni és indubtablement una font de transformació dels grups domèstics molt important. Les decisions sobre la residencia postnupcial determinen la reproducció dels grups domèstics generació rera generació i són, en gran mesura, responsables de l'actual distribució de diferents tipus d'agrupaments residencials.

En la meva investigació m'he centrat en les decisions residencials de més de 500 parelles després del matrimoni. Aquests casos han estat seleccionats com segueix. Només he retingut per a l'estudi aquells individus que encara residien a la comunitat el 1975, excloent aquells que originàriament varen celebrar 
el seu matrimoni i es varen assentar a la comunitat, però que més tard en varen marxar. D'entre els individus presents a la comunitat el 1975, m'he concentrar en aquells que eren o havien estat casats (p. ex., casats, vidus i divorciats) en el període 1941-1975 eliminant tots els solters i els que s'havien casat abans o després d'aquestes dates. De manera similar, han estat exclosos aquelis que es casaren durant aquest període però s'establiren originàriament fora de la comunitat. Sobre aquestes bases he aillat una població d'unes mil persones presents a la comunitat el 1975, que s'havien casat entre el primer de gener de $1941 \mathrm{i}$ el 31 de desembre de 1975 i que inicialment s'assentaren a la comunitat de Besalú després del seu matrimoni. Aquest procediment exclou, per exemple, els immigrants andalusos que podien haver falsejat les pautes catalanes de matrimoni i de formació familiar, però inclou en canvi un nombre substancial de pagesos que després de casar-se s'establiren en masos de la rodalia de Besalú i que més tard s'instal. laren a la vila i esdevingueren treballadors industrials.

En l'estudi es distingeixen tres tipus de residencia postnupcial: neolocal, referit a l'establiment dels nuvis en una residència distinta de la dels pares d'ell o d'ella; virilocal, quan la parella es trasillada a la residència dels pares del marit, i uxorilocal, quan la parella es trasllada a la residència dels pares de la muller.

\section{Resultats de la recerca}

En la primera part del període investigat (1941-1960), a l'àrea de poblament dispers, prop de quatre cinquenes parts dels matrimonis conduïen a la formació de famílies troncals. Aquests matrimonis seguien en gran mesura les normes tradicionals del dret català. De tota manera, la posició social i la riquesa dels pagesos eren variables importants. Els matrimonis uxorilocals, una cinquena part del total, i una quarta part dels que conduien a la formació de famflies troncals, eren una mica més freqüents entre els pagesos propietaris que entre els masovers. D'altra banda, entre els pagesos pobres predominaven les llars de farnílies simples sobre les compiexes. Això era degut probablement al fet que les parelles que es casaven neolocalment $(22,3 \%$ de tots els matrimonis rurals en el període 1941-1960) tendien a instal.lar-se a les masoveries més pobres, ja que eren les que quedaven desocupades més sovint.

En el nucli urbà de Besalú, durant els anys quaranta i cinquanta, els matrimonis associats amb la formació de llars complexes eren molt menys frequients que en l'àrea de poblament dispers $(55,7 \%$ contra $78,4 \%)$. Tanmateix, és difícil escatir la significació sociològica de la formació d'aquests grups residencials. D'una banda, en les condicions de precarietar econdmica i d'escassedat d'habitatge predominants en aquell temps (el període de la postguerra) afavorien aquest tipus de pràctica residencial. (Hem de recordar que fins a final dels anys cinquanta, quan es van dur a terme plans d'urbanització a Besalú, les construccions d'habitatges foren pràcticament inexistents.) Però, d'altra banda, les llars encapçalades per treballadors per compte propi (botiguers, industrials tradicionals, artesans, masovers) eren complexes, la qual cosa suggereix l'existència d'algun tipus d'associació econòmica entre pares i fills. De tota 
manera, la important proporció de matrimonis neolocals ( $44,3 \%$ del total) confirma el predomini de la família nuclear. En realitat, els jornalers sense terra, en general fadristerns fills de masovers pobres que no podien casar-se amb pubilles ni trobar cap mas vacant, es casaven majoritàriament de manera neolocal. El mateix podem dir de la petita proporció de treballadors assalariats de les indústries tradicionals.

Tanmateix, la interpretació de les dades esdevé difícil, ja que aquells que es casaven neolocalment eren al mateix temps els qui no podien fer res més, car, en ser fadristerns de masos de la rodalia de Besalú, si no volien restar solters havien d'emigrar forçosament a la vila en busca de feina i de parella. En general, podem dir que la família troncal, sent com era una forma familiar associada amb la possessió de la terra, la principal font de riquesa de la societat d'aquell temps, tenia un gran prestigi que afavoria la formació d'aquesta classe de família sempre i quan les condicions no ho impedissin.

Aquesta situació va canviar en gran mesura en la segona part del periode de l'estudi (1961-1975). L'augment de treballadors industrials i de població assalariada en general a la vila de Besalú van contribuir a l'expansió de la família nuclear. En aquest període més de la meitat dels matrimonis $(55,5 \%)$ determinaven la formació de llars de família nuclear. Però, tot i disminuir la importància relativa dels matrimonis que condüien a la formació de llars de família troncal, aquesta no va desaparèixer i es mantingué força bé. D'una banda, un gran nombre de treballadors autònoms de tota mena (propietaris de bars i restaurants, botiguers, carnissers, petits comerciants, erc.), principalment però no necessàriament d'origen camperol, van trobar en la família troncal un recurs oportú per tirar endavant els seus negocis, els quals no haurien pogut prosperar si haguessin hagut d'utilitzar mà d'obra assalariada. En segon jloc, un gran nombre de persones que immigraren a la vila i esdevingueren treballadors industrials, però que foren socialitzats en masos a partir dels valors de la familia troncal, tendien a formar llars complexes malgrat el fet que les tasques productives que desenvolupaven els pares $\mathrm{i}$ els fills casats que vivien junts ja no requerien llur cooperació econòmica. En la majoria de les famílies troncals d'aquests tipus s'observava la norma tradicional de compartir cuina i rebost i de portar comptes comuns, tot i que cap al final del període es perfilava una tendència cap a una privacitat creixent i a la separació entre les dues parelles casades.

Una de les pràctiques més corrents era la convivència d'un matrimoni ancià amb una de les seves filles casades. Aquesta filla no era una pubilla, una hereva, sinó una de les filles petites que en casar-se s'instal-lava a casa dels pares un cop casats els altres germans. Com que en aquest cas el propòsit de l'associació residencial no era la cooperació econòmica, sinó la millora del benestar de les dues parelles, era convenient que es quedés amb els pares una filla més que no pas un fill.

A l'àrea de poblament dispers la posició de la família troncal no tan sols es mantingué, sinó que fins i tot es va reforçar. Durant el període de 1961-1975 el $86,3 \%$ dels matrimonis van constituir famílies troncals. L'explicació d'aquest 
alt percentatge s'ha de buscar en l'emigració diferencial que resultava de l'abandó de les explotacions més pobres on, com ja sabem, predominava la família nuclear. Els escassos masos pobres que encara estaven ocupats ho eren per vells masovers que només conreaven un hortet o petites parcel.les de terra $i$ obtenien la major part dels seus ingressos del seu treball assalariat. La terra alliberada per l'abandonament d'aquestes masos pobres era llogada als arrendataris o propietaris d'explotacions agrícoles més viables que estaven en condicions d'invertir-hi capital a fi de modernitzar-les, ja que necessitaven extensions de terra més grans per poder fer rendibles les seves inversions a través de l'augment de l'escala de llurs operacions. En aquests tipus d'explotacions la família troncal adquirí un renovat vigor. Els agricultors mitjans, per poder fer front a les condicions d'una agricultura especialitzada, cada vegada més exigents en termes de mercat, es vegeren obligats a aplegar els seus recursos. Pares $i$ fills, apressats per la creixent demanda d'inversió de capital, havien de donar-se suport els uns als altres i negociar entre ells un contracte de societat. És en aquest context que podem interpretar el predomini aclaparador dels matrimonis virilocals (unes quatre cinquenes parts) entre els que determinaven la formació de families troncals. En contrast amb les pràcriques que afavorien els matrimonis uxorilocals entre els treballadors industrials urbans, a l'àrea d'assentament dispers la proporció de parelles que es casaven virilocalment era molt elevada.

\section{Reforma legislativa i canvi familiar}

En l'enumeració dels factors que determinen el canvi familiar, hem de donar especial relleu a la contribució específica de les refomes juridiques. Per raons de brevetat, tan sols n'esmentaré dues.

Malgrat que a principi dels anys quaranta el govern franquista acordà l'establiment d'un pla de jubilació i de seguretat social a càrrec de l'Estat, al principi només beneficiava la població assalariada industrial urbana. No fou fins a les reformes dels anys seixanta que la seguretat social es començà a estendre als treballadors autonoms i als pagesos. Va ser precisament en aquest període quan, a Besalú, van començar a aparèixer noves pràctiques familiars. Cal tenir en compte que l'establiment d'un sistema de seguretat social ensems amb l'extensió del treball assalariat són els factors més importants que afavoreixen la difusió de la família nuclear. En el nostre cas, però, aquest efecte s'ha vist afeblit per l'adaptació de la família troncal a la nova situació, una velia institució a la recerca de nous significats.

Fou també el 1960 quan fou aprovada la Compilació de Dret Civil Catałà. Quan es va codificar el dret civil espanyol als anys vuitanta del segle passat, l'aspiració racionalista d'un sol cos jurídic unificat per a tot el territori de l'Estat es vegé frustrada en gran part a causa de l'oposició dels grans terratinents, majoritàriament catalans (Puig i Roca, 1984:3). Sens dubte, aquests esforços a favor de la preservació del dret foral constituïen el rerafons d'un moviment embrionari, encara poc articulat, que havia de conduir a la formulació del catalanis- 
me polític conservador. Es va acordar que s'aprovaria un apèndix al codi civil per a cadascuna de les regions que disposaven d'un dret civil foral, com era el cas de Catalunya. Malgrat tot, per una acumulació de circumstàncies, el pla fou posposat $i$ l'apèndix no va ser redactat fins al 1960 . Per tant, fins a aquesta data, el dret civil català, tot i ser conegut i observat pels advocars i particularment pels notaris i aplicat pels tribunals de Catalunya, tenia un caràcter marcadament consuetudinari tenint en compte que la darrera recopilació de les lleis catalanes es remuntava a principi del segle XVIII.

La compilació de 1960 contenia gran part del dret civil català, sobretot pel que fa al dret de família i successori. Segurament la intenció dels juristes que van promoure la compilació de 1960 era preservar, i fins i tot fer reviure, les velles institucions del dret català per tal de fer front a forces amenaçadores tals com la industrializzació i la intervenció de l'Estat, que sens dubte representaven un perill d'erosió en absència d'un autogovern català propi que propiciés la seva renovació legislativa. S'ha de remarcar que la compilació de 1960 fou aprovada en uns moments en què l'economia espanyola iniciava un període d'expansió després de la llarga crisi dels anys qutaranta i cinquanta, i quan l'observança del dret successori català havia decaigut a les ciutats com a resultat de la introducció i difusió general dels valors capitalistes $i$ individualistes. D'altra banda, la manca d'institucions públiques d'autogovern, prohibides pels vencedors de la guterra civil, ha impedir fins a una data molt recent l'adaptació del dret civil català a les condicions modernes. Això significa que la resposta del complex institucional de la família troncal a la nova situació fou més aviat una quiestió pràctica, en absència d'una regulació específica destinada a posar-la al dia.

\section{Conclusió}

Tornem al nostre problema inicial: Com canvien les formes familiars tradicionals sota l'impacte de la industrialització i com s'efectua la transició d'una forma familiar majoritària a una altra? Durant els anys quaranta el funcionament de la família troncal com a forma familiar predominant a la societat de Besalú era mantinguda per la institució jurídica dels capírols matrimonials, que establien una cooperació econòmica entre els pares i un dels seus fills casats i condicionaven l'herència de la propietat a la continuació de la convivència $i$ de la col-laboració en ells. Aquestes normes jurídiques estaven relacionades amb una mena de produccio tradicional, que he anomenat el sistema de masos, que requeria la transmissió indivisible de la terra generació rera generació. Quan als anys seixanta va començar la industrialització, tot i que aquesta institució jurídica perdé gran part del seu sentit, la família troncal mantingué un elevat prestigi, ja que era la forma de residència preferida pels terratinents i els estrats de població més rics. Bastant paradoxalment, els grans terratinents que havien abandonat les seves masies des de feia temps per anar a viure a les ciutats foren els primers a acceptar la divisió igualitària de les seves propietats entre els seus fills, ja que en no poder viure només de les rendes de la terra, l'herència indivisible havia perdut el sentit que tenia per ells. 
Aquesta adhesió continuada a la família troncal troba la seva expressió en l'augment de dues noves varietats de formes familiars: (1) la convivència en el nucli urbà d'una filla casada amb els seus pares en vista de la millora recíproca del seu benestar (la parella anciana rep atencions dels joves com a contrapartida de la seva cura dels néts) i (2) l'associació econòmica entre els pares i el seu primogenit en les explotacions econòmicament viables que requerien una elevada capitalització.

Malgrat aquestes novetats, val a dir que els valors de privacitat essencials en la fámília nuclear s'estan difonent ràpidament entre la població de Besalú. No només els assalariats prefereixen viure pel seu compte després del matrimoni, sinó que també hi ha molts treballadors autonoms, que de fet cooperen econòmicament amb els seus pares i per als quals la família troncal podria continuar tenint sentit, que opten per una residència separada quan es casen. L'expansió urbanística i la construcció continuada d'habitatges dels últims anys probablement hi han contribuitt.

La transició de la familia troncal a la família nuclear encara no s'ha acabat $i$ és diffcil de dir si es produirà del tot. Besalú encara està en aquest aspecte molt lluny de Barcelona, on el 1981 les llars complexes només representaven el $13,5 \%$ del total (Soler, 1985).

Les dades disponibles des del final del meu treball de camp són testimoni de la resistència d'una institució que refusa morir malgrat les pressions de les forces modernitzadores de la societat ${ }^{2}$. Es fa difícil de dir si les esmentades pràctiques sobre l'adaptació de la família troncal a les noves condicions econòmiques i socials esdevindran institucionalitzades en el decurs del temps o desapareixeran com a conseqüència de la creixent modernització de Besalú.

\section{Bibliografia}

Augustrns, G. (1977). "Reproduction sociale et changement social: l'exemple des Baronnies". Revue française de sociologie, núm. 18, p. 465-484.

Barrera GonzAlez, A. (1990). Casa, herencia y familia en la Cataluña rural. Madrid: Alianza.

Berkner, L. (1972a). "The Srem-Family and the Developmental Cycle of the Peasant Household: An Eighteenth Century Austrian Example». American Historical Review, núm. 77, p. 398-418.

- (1972b). «Rural Family Organisation in Europe: A Problem in Comparative History". Peasant Studies Newsletter, núm. 1, p. 145-156.

2. J.M. Calvet m'informà personalment dels resultats de la seva recerca sobre la composició de les llars a diferents zones de Catalunya. La seva anàlisi sincronica de l'esrructura de la llar a la zona de Besalú basada en el cens de 1981 revela un increment de llars complexes, tant en l'àrea urbana com en la de poblament dispers. Tanmateix, i com que la classificació de llars que ell utilizza no és exactament la mateixa que la meva, $\mathrm{i}$ a causa de la possible interferència de facrors de canvi demogràfic, aquesta dada s'hauria de prendre amb cautela. Esperem que la imminent publicació dels resultats del cens de 1991 pel que fa a la composicio de les llars pugui aportar algunes clarícies sobre aquesta quüestió. 
BERKNER, L. (1973). "Recent Research on the History of the Family in Western History". Journal of Marriage and the Family, p. 395-405.

- (1975). "The Use and Misuse of Census data for Historical Analysis of Family Structure». Joumal of Interdisciplinary History, num. 5, p. 721-738.

BERKNeR, L.K. \& MENDELS, F.F. (1976). "Intheritance Systems, Family Structure, and Demographic Patterns in Western Europe (1700-1900)". A Ch. Thlly.(ed.) Historical Studies of Changing Fertility. Princeton: Princeron Universicy Press.

BRoCA, G.M. DE \& AMELl, J. (I880). Instituciones del Derecho Civil Catalán Vigente. Barcelona: Imprenta barcelonesa.

BYres, T.J. (1983). "Historical Perspectives on Sharecropping". A T.J. BYres (ed.) Sharecropping and sharecroppers. Londres: Frank Cass, p. 7-40.

Compilación de Derecho Civil Especial de Cataluña (1960). Madrid: Boletín Oficial del Estado.

FiNE-SOURIAC, A. (1977). «La famille-souche pyrénéenne au Xixè siècle: Quelques réflexions de méthode". Annales, núm. 32, p. 478-487.

FiAQUER, Ll. (1984). "Evaluación crítica de las distintas metodologías para el estudio de las familias troncales campesinas". A E. SEvilia GuZmán (ed.) Sobre agricultores y campesinos. Estudios de sociologia rural de España. Madrid: Servicio de Publicaciones Agratias. p. 251-272.

Flaquer, LI. \& SOLer, J. (1990). Pemanencia y cambio en la familia española. Madrid: Centro de Investigaciones Sociológicas.

HarRIS, C.C. (1986). Familia y sociedad industrial. Barcelona: Península.

IGLFSIAS, ]. (1958). Derecho Romano. Instituciones del derecho pritudo. Barcelona: Ariel.

Kellerhals, J. et al. (1984). Microsociologie de la famille. París: Presses Universitaires de France.

Lamaison, P. (1979). "Les stratégies matrimoniales dans uns système complexe de parente: Ribennes en Gévaudan (1650-1830)n. Annales, núm. 34, p. 721-743.

LasLetT, P. (1972). "Introduction: The History of the Family". A P. LASLetT $8 x$ R. WaLl (ed.) Household and Family in Past Time. Cambridge: Cambridge University Press, p. 1-89.

LE ROY LADURie, E. (1976). «Family Structures amd Inheritance Customs in Sixteenth Century France". A J. Goody, J. THirsk \& E.P. Thompson (ed.) Family and Inheritance. Cambridge: Cambridge University Press, p. 33-70.

Maspons i Anglasell, F. (1935). La llei de la familia catalana. Barcelona: Batcino.

- (1935). El règim successori català. Barcelona: Barcino.

Parish, W.L. \& SCHWarTZ, M. (1972). "Household Complexity in Nineteenth Centary France". American Sociological Review. núm. 37, p. 545-173.

PUig i FerRiot, L. \& Roca I Trias, E. (1984). Institucions de Dret Civil de Catalunya. Barcelona: Bosch.

SABEAN, D. (1976). "Aspects of Kinship Behaviour and Property in Rural Western Europe Before 1800 . A J. GOOOY, J.THIRSK \& E.P. ThOMPSON (ed.) Family and Inberitance. Cambridge: Cambridge University Press, p. 96-111.

SARDÀ I CORTES, F. (1962). L'actual sistema successori català. Barcelona: Dalmau.

SilvermaN, S.F. (1968). "Agticultural Organization, Social Structure and Values in Italy: Amoral Familism Reconsidered". American Anthropologist, núm. 70, p. I-20.

SOLER, J. (1985). "La escructura del hogar en Barcelona: Un análisis del padrón de 1981 ". Boletín de la Asociación de Demografia Histórican núm. 3, p. 51-75.

Verdon, M. (1979). "The Stem Family: Toward a General Theory". Journal of Interdisciplinary History, núm. 10, p.87-105. 
Verdon, M. (1980). "Shaking Off the Domestic Yoke or the Sociological Significance of Residence». Comparative Studies in Society and History, núm. 22, p. 109-132.

VILA-VALENTf, J. (1973). El món rural a Catalunya. Barcelona: Curial.

WACHTER, K.W.; HAMMEL, E.A. \& LASLETT, P. (1978). Statistical Studies of Historical Social Structure. Nova York: Academic Press.

WhEATON, R. (1975). "Family and Kinship in Western Europe: The Problem of the Joint Family Household». The Journal of Interdisciplinary History, núm. 4, p. $601-628$.

YVER, J. (1966). Egalité entre héritiers et exclusion des enfants dotés. Essai de géographie coutumière. París: Sitey. 